\title{
SÍNTESE DE ÉSTERES DE ETILA A PARTIR DA BIOTRANSFORMAÇÃO DO ÓLEO DE COCO POR DIFERENTES LIPASES IMOBILIZADAS
}

\author{
A. K. F. CARVALHO ${ }^{1}$, H. B. S. BENTO ${ }^{1}$, A. S. V. NICO ${ }^{1}$, J. C. S. BARBOSA ${ }^{1}$, \\ H. F. de CASTRO ${ }^{1}$ \\ ${ }^{1}$ Universidade de São Paulo, Escola de Engenharia de Lorena, Dep. de Engenharia Química \\ E-mail para contato: anacarvalho@usp.br
}

\begin{abstract}
RESUMO - O objetivo deste trabalho foi verificar a eficiência de diferentes lipases imobilizadas, tais como lipase de Burkholderia cepacia imobilizada em $\mathrm{SiO}_{2}$-PVA e terra diatomácea e lipase de Candida antactica (Novozym ${ }^{\circledR} 435$ ) na etanólise do óleo de coco. As reações foram efetuadas em condições fixas empregando 20 gramas de meio reacional na razão molar óleo/ etanol de $1: 8,50^{\circ} \mathrm{C}$ e agitação magnética de 150 rpm por 48 horas. Os produtos obtidos foram quantificados por cromatografia de fase gasosa, espectroscopia de ressonância magnética nuclear e cromatografia líquida de alta eficiência. As amostras de biodiesel sintetizadas pelas diferentes lipases apresentaram elevada conversão $(>96 \%)$ e os valores de viscosidade atenderam o limite especificado pela ANP. Entre as lipases testadas, a Novozym ${ }^{\circledR} 435$ apresentou melhor desempenho, convertendo 98,4\% dos triglicerídeos em éster e produzindo baixos teores de mono e diglicerídeos.
\end{abstract}

\section{INTRODUÇÃO}

A biocatálise consiste nas reações catalisadas por enzimas obtidas de diversas fontes, tais como culturas puras de microrganismos (células integras), células de plantas, enzimas puras ou parcialmente purificadas, que encontraram um campo inexplorado de aplicações, permitindo o desenvolvimento de produtos e processos inovadores que não somente são competitivos, como também atendem aos critérios de sustentabilidade (Yan et al., 2014; Hwang et al., 2014).

A utilização de enzimas na indústria apresenta um crescimento exponencial devido às vantagens em relação aos catalisadores químicos, como a elevada atividade catalítica em condições brandas de temperatura e pressão e a elevada especificidade. Dentre as diversas enzimas utilizadas industrialmente, as lipases (triacilglicerol acil hidrolases, EC 3.1.1.3) são os biocatalisadores responsáveis por catalisar reações de hidrólise de óleos em ácidos graxos livres, monoacilgliceróis, diacilgliceróis e glicerol. Além da hidrólise, as lipases também são capazes de catalisar reações reversas, como esterificação e transesterificação (interesterificação, alcóolises e acidólises) (Christopher et al., 2014).

A rota enzimática para a produção de biodiesel é atrativa, uma vez que as enzimas são biodegradáveis e apresentam maior compatibilidade com as variações de qualidade das matériasprimas e são capazes de produzir o biodiesel em condições reacionais brandas, levando à redução 
do consumo energético e da quantidade de água residual gerada no processo (Hwang et al., 2014; Christopher et al., 2014).

O presente trabalho teve como objetivo verificar a eficiência de diferentes lipases imobilizadas, tais como lipase de Burkholderia cepacia imobilizada em $\mathrm{SiO}_{2}-\mathrm{PVA}$ e terra diatomácea e Candida antactica (Novozym $\left.{ }^{\circledR} 435\right)$ na etanólise do óleo de coco.

\section{MATERIAIS E MÉTODOS}

\subsection{Reagentes}

Como reagentes foram utilizados: etanol anidro (99\%, Cromoline) e óleo de coco adquirido da FRESCOCO (São Paulo-SP), tendo uma composição aproximada em ácidos graxos de: 8,9\% Caprílico, 6,2\% Cáprico, 47,1\% Láurico, 18,8\% Mirístico, 7,9\% Palmítico, 2,6\% Esteárico, 6,1\% Oleico e 1,6\% Linoleico. Outras características da amostra do óleo de coco incluem: massa

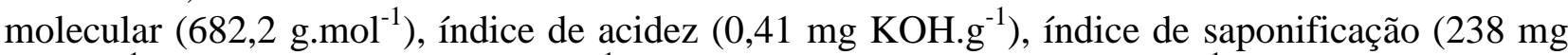
$\left.\mathrm{KOH} \cdot \mathrm{g}^{-1}\right)$, índice de iodo $\left(25 \mathrm{~g} \mathrm{I}_{2} \cdot \mathrm{g}^{-1}\right)$, índice de peróxido $\left(0,36 \mathrm{mEq} \cdot \mathrm{kg}^{-1}\right)$ e viscosidade $(29,0$ $\left.\mathrm{mm}^{2} \cdot \mathrm{s}^{-1}\right)$.

\subsection{Biocatalisadores}

Como biocatalisadores utilizou-se a preparação comercial de lipase microbiana de Burkholderia cepacia imobilizada em suporte híbrido de sílica-álcool polivinílico (BCL $\mathrm{SiO}_{2^{-}}$ PVA) e em terra diatomácea (Lipase PS-IM) manufaturada pela Amano (Nagoya-Japão) e lipase de Candida antactica Lipase B imobilizada em resina acrílica macroporosa (Novozym ${ }^{\circledR} 435$ ) manufaturada pela Novozymes (Dinamarca). O composto $\mathrm{SiO}_{2}-\mathrm{PVA}$ foi preparado e ativado com epicloridrina de acordo com metodologia descrita por Da Ros et al. (2010). A recuperação dos derivados imobilizados foi efetuada por filtração a vácuo, com lavagens sucessivas com hexano até a redução da umidade do derivado imobilizado em valor não superior a $15 \%$. A atividade da

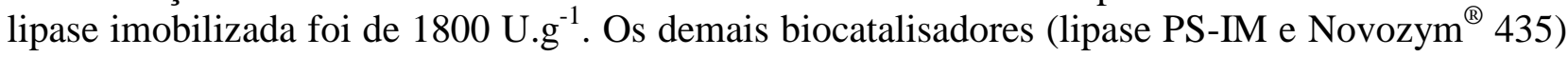
foram adquiridos na forma imobilizada da Sigma-Aldrich (Brasil).

\subsection{Síntese de biodiesel}

As reações foram efetuadas em reatores de vidro cilíndrico encamisados $(50 \mathrm{~mL})$, acoplados com condensador de refluxo nas seguintes condições fixas: 20 gramas de meio reacional na razão molar óleo/etanol de 1:8; $10 \%$ de biocatalisador em relação à massa de meio reacional $(2,0 \mathrm{~g}) \mathrm{e}$ agitação magnética de $150 \mathrm{rpm}$. O aparato experimental usado nas reações é mostrado na Figura 1.

A síntese catalisada pela lipase $\mathrm{BCL} \mathrm{SiO}_{2}$-PVA foi efetuada a $45^{\circ} \mathrm{C}$ por um período de $72 \mathrm{~h}$ e o progresso da reação acompanhado pela retirada de alíquotas a cada $24 \mathrm{~h}$. As sínteses catalisadas por Novozym ${ }^{\circledR} 435$ e Lipase PS-IM foram realizadas a $60^{\circ} \mathrm{C}$ durante $48 \mathrm{~h}$ e o progresso da reação foi acompanhado pela retirada de alíquotas a cada $12 \mathrm{~h}$. 


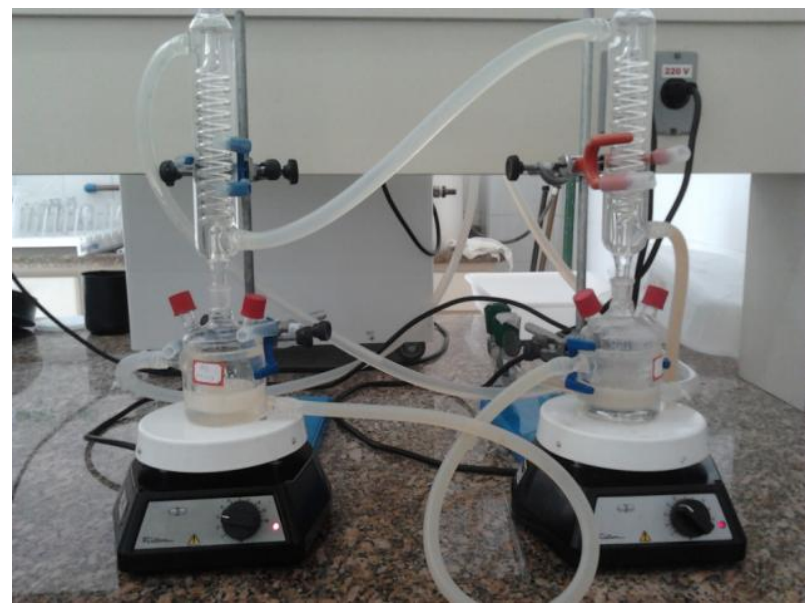

Figura 1 - Aparato experimental utilizado nas reações de transesterificação.

\subsection{Monitoramento da formação de ésteres de etila}

O progresso da reação foi acompanhado pela retirada de alíquotas ao longo da reação e as concentrações de ésteres de etila foram quantificadas por cromatografia de fase gasosa (Cromatógrafo a gás Varian 3800) utilizando hexanol como padrão interno, conforme metodologia descrita por Urioste et al. (2008).

\subsection{Purificação das amostras e análises do produto purificado}

Ao término das reações o catalisador foi separado do meio por filtração. Ao meio filtrado foi adicionado o mesmo volume de água destilada e a mistura foi transferida para um funil de decantação, permanecendo por 30 min para a separação das fases. A fase inferior composta por glicerol e água de lavagem foi descartada e a fase superior composta pelos ésteres de etila (biodiesel) foi submetida à centrifugação (1570 g por $15 \mathrm{~min})$ e em seguida a evaporação em rotaevaporador para a retirada de etanol. Posteriormente, foram adicionadas pequenas quantidades de sulfato de sódio anidro para finalizar a etapa de secagem.

As amostras purificadas foram analisadas quanto ao teor de ésteres de etila tomando por base os dados gerados por espectroscopia de ressonância magnética nuclear $\left(\mathrm{RMN}^{1} \mathrm{H}\right)$ utilizando a equação validada por Paiva et al., (2013). Os teores residuais de monoglicerídeos (MAG), diglicerídeos (DAG) e triglicerídeos (TAG) foram quantificados por cromatografia líquida de alta eficiência (CLAE). Os valores de densidade foram determinados utilizando um densímetro digital Modelo DMA 35n EX (Anton Paar). As medidas foram feitas a $20^{\circ} \mathrm{C}$, empregando-se $2,0 \mathrm{~mL}$ da amostra. A viscosidade absoluta em função da taxa de deformação foi determinada utilizando-se viscosímetro Brookfield Modelo LVDVII (Brookfield Viscometers Ltd, Inglaterra) empregando o cone $\mathrm{CP} 42$. As medidas de viscosidade foram feitas empregando $1 \mathrm{~mL}$ de amostra a $40^{\circ} \mathrm{C}$.

\section{RESULTADOS E DISCUSSÃO}

Atualmente, a maior parte dos óleos utilizados na produção de biodiesel possui ácidos graxos predominantemente insaturados o que torna esse combustível susceptível à oxidação, principalmente quando estocado por longos períodos. As substâncias geradas pela degradação 
oxidativa do biodiesel comprometem tanto a qualidade do combustível quanto o funcionamento dos motores que o utilizam (Tang et al., 2008; Atabani et al., 2013). No entanto, o óleo de coco apresenta uma composição predominantemente de ácidos graxos saturados (Nevin; Rajamohan, 2004). Essa característica, pouco comum entre os óleos de origem vegetal, confere a estes óleos uma elevada resistência à oxidação, o que representa um importante fator para a adesão desses óleos como matérias-primas para a produção de biodiesel (Tupufia et al., 2013; Atabani et al., 2013).

Ao longo das reações, efetuou-se o monitoramento da formação de ésteres de etila em função do tempo de reação por cromatografia em fase gasosa (CG), conforme apresentado nas Figuras 2 (a, b e c). Os rendimentos de transesterificação foram confirmados por $\mathrm{RMN}{ }^{1} \mathrm{H}$ (Figuras $3 \mathrm{a}$, b e c) e CLAE (tomando por base os teores de mono, di e triglicerídeos).

a)

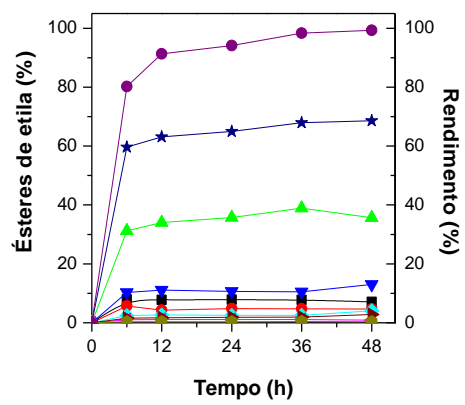

b)

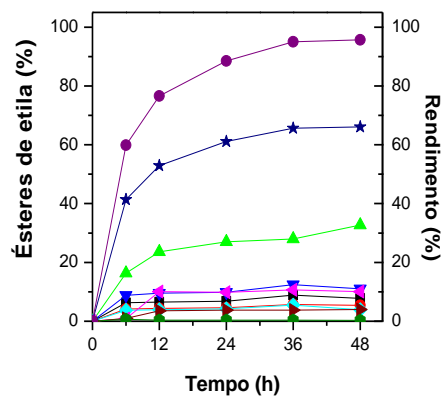

c)

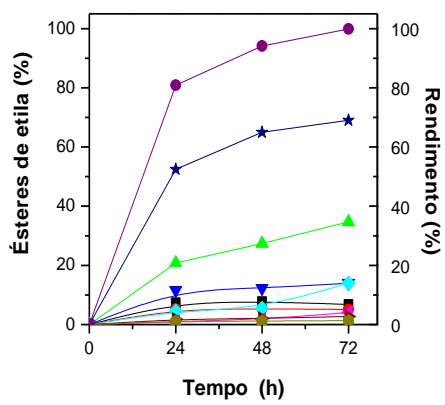

Figura 2- Perfil de formação dos ésteres de etila (concentração mássica, \%) na reação de etanólise

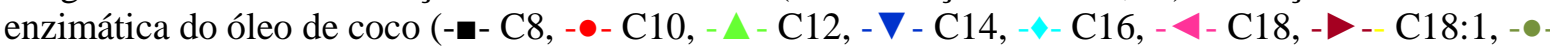

C18:2, -*-Total) com o correspondente rendimento (\%) no eixo y da direita (-๑-) catalisada pela enzima: a) Novozym $^{\circledR} 435$; b) PS-Diatomácea, c) BCL-SiO ${ }_{2}$-PVA.

Todas as lipases foram eficientes na reação de etanólise de óleo de coco, alcançando elevada conversão (> 96\%) entre 36 a 72 h de reação, dependendo da enzima e da temperatura utilizada no processo. $\mathrm{O}$ principal éster produzido em todas as reações foi o laurato de etila $\left(\mathrm{C}_{12: 0}\right)$, sendo os outros ésteres produzidos em menor concentração. Este perfil encontra-se dentro do esperado, tendo em vista que a composição do óleo de coco é constituída predominantemente de ácido láurico.

Nas Figuras 3 (a, b e c) é possível visualizar a presença de um quarteto em 4,1 ppm, referente aos hidrogênios metilênicos da porção alcoólica do éster $\left[\mathrm{CH}_{3}-\mathrm{CH}_{2}-\mathrm{OC}(=\mathrm{O})-\mathrm{R}\right]$. A partir da análise dos sinais foi possível confirmar a elevada conversão em ésteres de etila pela técnica de RMN ${ }^{1} \mathrm{H}$, cujos resultados foram: $98,4 \%, 96,0 \%$ e $98,0 \%$ para Novozym ${ }^{\circledR} 435$, Lipase PS IM e BCL-SiO ${ }_{2} \mathrm{PVA}$, respectivamente. Esses resultados são semelhantes aos relatados na literatura científica. Tupufia et al., (2013) realizaram a etanólise do óleo de coco mediada por Novozym $^{\circledR} 435$ e alcançaram rendimentos superiores a 94\%. Encinar et al., (2010) testaram diferentes tipos de lipases, tais como Lipozyme TL IM, Novozym 435 and Pseudomonas cepacia e todas foram capazes de promover elevadas conversões (95-98\%) em ésteres de etila. 


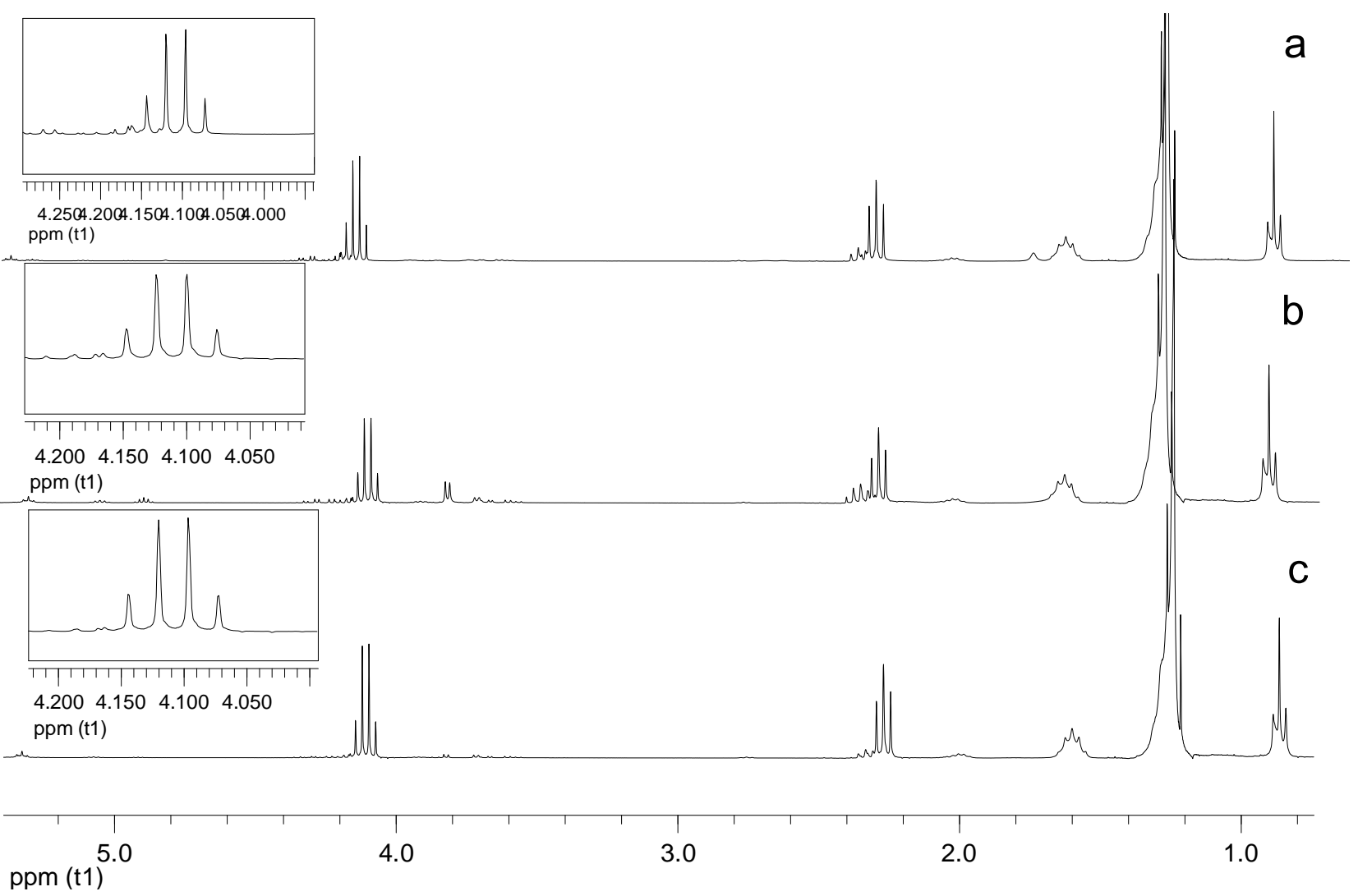

Figura 3 - Espectro RMN ${ }^{1} \mathrm{H}$ integrado de biodiesel obtido a partir da etanólise de óleo de coco catalisada com: a) Novozym ${ }^{\circledR} 435$; b) PS-Diatomácea, c) BCL-SiO 2 -PVA.

A comparação do desempenho das diferentes lipases na síntese de biodiesel pela rota etanólica foi analisada em função da formação de ésteres de etila e quantificação de mono-ediglicerídeos.

$\mathrm{Na}$ Tabela 1 são apresentadas as propriedades das amostras purificadas, bem como as concentrações de ésteres obtidas a partir da média das conversões calculadas pelas técnicas de RMN ${ }^{1} \mathrm{H}, \mathrm{CG}$ e CLAE. Entre as lipases testadas, a Novozym ${ }^{\circledR} 435$ apresentou melhor desempenho, fornecendo um produto com maior conteúdo em ésteres $(98,4 \%)$ e baixos teores de mono $(1,2 \%)$ e diglicerídeos $(0,4 \%)$.

Tabela 1 - Propriedades das amostras purificadas obtidas na etanólise enzimática de óleo de coco.

\begin{tabular}{|l|c|c|c|c|c|c|}
\hline Biocatalisador & $\begin{array}{c}\text { Densidade } \\
\left(\mathbf{g . c m}^{-\mathbf{3}} \mathbf{)}\right.\end{array}$ & $\begin{array}{c}\text { Viscosidade } \\
\left(\mathbf{m m}^{\mathbf{2} . \mathbf{s}} \mathbf{\mathbf { - 1 }}\right.\end{array}$ & $\begin{array}{c}\text { MAG } \\
\mathbf{( \% )}\end{array}$ & $\begin{array}{c}\text { DAG } \\
(\mathbf{\%})\end{array}$ & $\begin{array}{c}\text { TAG } \\
(\mathbf{\%})\end{array}$ & $\begin{array}{c}\text { Concentração } \\
\text { de ésteres (\%) }\end{array}$ \\
\hline Novozym 435 & 0,8764 & 3,27 & 1,2 & 0,4 & 0 & 98,4 \\
\hline PS-Diatomácea & 0,8242 & 5,34 & 2,4 & 1,6 & 0 & 96,0 \\
\hline BCL-SiO $_{2}$ PVA & 0,8760 & 3,76 & 1,3 & 0,7 & 0 & 98,0 \\
\hline
\end{tabular}


Os valores de viscosidade cinemática encontram-se dentro da faixa limite especificada pela legislação da ANP: $\left(3,0-6,0 \mathrm{~mm}^{2} \cdot \mathrm{s}^{-1}\right)$, com valores que variaram de 3,27 a $5,34 \mathrm{~mm}^{2} \cdot \mathrm{s}^{-1}$. Os rendimentos estão de acordo com a especificação da ANP que instituiu um limite mínimo de $96 \%$ $\mathrm{m} / \mathrm{m}$ de ésteres de etila. Quanto aos teores de monoglicerídeos e diglicerídeos nenhuma amostra correspondeu aos limites mínimos estabelecidos que são de 0,80 e $0,20 \% \mathrm{~m} / \mathrm{m}$ respectivamente (ANP 2014). No entanto, em todas as amostras não foram identificados triglicerídeos, o que demonstra a eficiência das reações promovidas pelas enzimas imobilizadas.

\section{CONCLUSÃO}

O conjunto de resultados obtidos mostra que todas as lipases testadas como catalisador foram eficientes na conversão dos ácidos graxos presentes no óleo de coco em ésteres de etila. Os valores de viscosidade das amostras atenderam as normas oficiais para uso como biocombustível. Conclui-se, portanto, que as lipases possuem grande potencial de aplicação em diversos processos industriais incluindo o setor de biocombustíveis, uma vez que são energeticamente eficientes fáceis de controlar e possuem alto grau de especificidade, o que as tornam atrativas no ponto de vista industrial e econômico.

\section{REFERÊNCIAS}

ANP. Disponível em http://www.anp.gov.br/?g=60467\&m=\&t1=\&t2=\&t3=\&t4=\&ar=\&os=\&c achebust=1382034774841. Acesso em 2 de abril de 2014.

ATABANI, A. E.; MAHLIA, T. M. I.; MASJUKI, H. H.; BADRUDDINA, I. A.; YUSSOF, H. W.; CHONGA, W. T.; LEE, K. T. A comparative evaluation of physical and chemical properties of biodiesel synthesized from edible and non-edible oils and study on the effect of biodiesel blending. Energy, v. 58, p. 296-304, 2013.

CHRISTOPHER, L. P.; KUMAR, H.; ZAMBARE, V. P. Enzymatic biodiesel: Challenges and opportunities. Appl. Energy, v. 119, p.497-520, 2014.

DA RÓS, P. C. M.; SILVA, G. A. M.; MENDES, A. A.; SANTOS, J. C.; DE CASTRO, H. F. Evaluation of the catalytic properties of Burkholderia cepacia lipase immobilized on noncommercial matrices to be used in biodiesel synthesis from different feedstocks. Bioresour. Technol., v.101, p. 5508-5516, 2010.

ENCINAR, J. M.; GONZÁLEZ, J. F.; MARTÍNEZ, G.; ROMÁN, S. Biodiesel by enzymatic transesterification of sunflower oil with ethanol. J. Biobased Mater. Bioenergy, v. 4, p. 8794, 2010.

HWANG, H. T., QI, F.; YUAN, C.; ZHAO, X.; RAMKRISHNA, D.; LIU, D.; VARMA, A. Lipase-catalyzed process for biodiesel production: protein engineering and lipase production. Biotechnol. Bioeng., v. 111, p. 639-653, 2014.

NEVIN, K. G.; RAJAMOHAN, T. Beneficial effects of virgin coconut oil on lipid parameters and in vitro LDL oxidation. Clin. Biochem., v. 37, p. 830-835, 2004. 
PAIVA, E. J. M.; DA SILVA, M. L. C. P.; BARBOZA, J. C. S.; OLIVEIRA, P. C.; DE CASTRO, H. F.; GIORDANI, D. S. Non-edible babassu oil as a new source for energy production - a feasibility transesterification survey assisted by ultrasound, Ultrason Sonochem., v. 20, p. 833-838, 2013.

TANG, H.; WANG, A.; SALLEY, S. O.; SIMON, K. Y. N. The effect of natural and synthetic antioxidants on the oxidative stability of biodiesel. J. Am. Oil Chem. Soc., v.85, p. 373-382, 2008 .

TUPUFIA, S.; JEON, Y. J.; MARQUIS, C.; ADESINA, A. A.; ROGERS, P. L. Enzymatic conversion of coconut oil for biodiesel production. Fuel Process. Technol., v. 106, p. 721726, 2013.

URIOSTE, D.; CASTRO, M. A. B.; BIAGGiO, F. C.; DE CASTRO, H. F. Síntese de padrões cromatográficos e estabelecimento de métodos para dosagem da composição de ésteres de ácidos graxos presentes no biodiesel a partir do óleo de babaçu. Quim. Nova, v. 31, p. 407412, 2008.

YAN, Y.; LI, XIANG, WANG, G.; GUI, X.; SU, F., WANG, X.; LIU, T. Biotechnological preparation of biodiesel and its high-valued derivatives: A review. Appl. Energy, v. 113, p. 1614-1631, 2014. 